https://helda.helsinki.fi

\title{
Wittgenstein and the Limits of Language
}

Routledge

2020

Appelqvist , H (ed.) 2020 , Wittgenstein and the Limits of Language . Routledge Studies in

Twentieth-Century Philosophy, vol. 48 , Routledge , New York, NY . https://doi.org/10.4324/9781351202671

http://hdl.handle.net/10138/330244

https://doi.org/10.4324/9781351202671

unspecified

acceptedVersion

Downloaded from Helda, University of Helsinki institutional repository.

This is an electronic reprint of the original article.

This reprint may differ from the original in pagination and typographic detail.

Please cite the original version. 
Author's manuscript. Final version published in Hanne Appelqvist (ed.) Wittgenstein and the Limits of Language, Routledge 2020, pp. 1-23.

\section{Introduction}

\section{Hanne Appelqvist}

\section{The Early View}

\subsection{Logic as the Limit of the World}

In the Preface of Tractatus Logico-Philosophicus, Wittgenstein writes that "the aim of the book is to draw a limit to thought, or rather - not to thought, but to the expression of thoughts: for in order to be able to draw a limit to thought, we should have to find both sides of the limit thinkable" (TLP, 3, see TLP 4.114). According to the traditional interpretation of the book, this task is accomplished by presenting a theory of linguistic sense, known as the picture theory of meaning. According to this theory, every meaningful proposition is a picture of a possible state of affairs. The picturing of states of affairs requires, in turn, referential relations between the elements of the picture and the pictured and the ability of those elements to be connected with one another as the elements of the pictured state of affairs are connected (TLP 2.1514, 2.151). This structural isomorphism between the picture and the pictured is made possible by logical form shared by language and the world (TLP 2.033, 2.17). When a proposition is analyzed into its simple elements, i.e. names, each name, as a constituent of the proposition, has a logical form that corresponds to the form of the object to which it refers in the state of affairs. The logical forms of objects thus ground the logical form of states of affairs as well as of the propositions depicting them. Hence, Wittgenstein writes, "Logic pervades the world: the limits of the world are also its limits" (TLP 5.61). 
It follows from the Tractarian dictum, according to which meaningful propositions are pictures of possible states of affairs, that language is strictly factual. According to the Tractatus, all meaningful propositions are bipolar, capable of being true and capable of being false (TLP 2.21, 4.023). Moreover, in the Tractarian account, "the totality of true propositions is the whole of natural science" (TLP 4.11). Hence, when Wittgenstein sets out to draw a limit to the expression of thought, this translates into the philosophical task of setting "limits to the much disputed sphere of natural science" (TLP 4.113). However, in its attempt to draw such limits, the practice of philosophy in the Tractatus cannot abide by its self-proclaimed standard, namely "to say nothing except what can be said, i.e. propositions of natural science - i.e. something that has nothing to do with philosophy" (TLP 6.53). If the philosophical goal of the Tractatus is to delineate sense from nonsense by laying out the conditions for sense, those conditions are not among the facts expressible in language (TLP 2.172). One cannot step outside the bounds of thought to form metathoughts on the preconditions of sense that would themselves satisfy those conditions. Instead, Wittgenstein claims, logical form is "shown" or "displayed" in propositions (TLP 2.172, 4.121$4.122,6.22)$. According to the traditional interpretation of the Tractatus, his is the reason why Wittgenstein declares his own propositions nonsensical (TLP 6.54).

The status of logical form as the limit of language surfaces in Wittgenstein's treatment of propositions of logic. Every imaginable state of affairs, i.e., every possibility, can be expressed in language, and there are no thoughts in the technical sense of the Tractatus indicating bipolarity that could not be expressed by means of propositions. However, there are two limiting cases of propositions that do not fulfill the standard of bipolarity but that are not nonsensical either. These are tautologies and contradictions. Tautologies are unconditionally true, while contradictions are true under no conditions. Hence, given that they fail to "restrict reality to two alternatives: yes or no", tautologies and contradictions are senseless (sinnlos) (TLP 4.023). Nevertheless, as they still manifest logical form, if not empirical content, tautologies and contradictions are not nonsensical 
(unsinnig) (TLP 4.46-4.464). In Wittgenstein's view, propositions of logic are tautologies. While they do not say anything about the contingent facts comprising reality, they show "the logic of the world" (TLP 4.462, 6.22). They show the pure contentless form of language and thereby reveal its limits (TLP 6.12).

Wittgenstein's conception of the limits of meaningful language leaves the Tractatus itself in a puzzling position. What are we to think of the program outlined by Wittgenstein if it renders the sentences of the Tractatus itself nonsensical pseudo-propositions? How are we supposed to understand those sentences if they fail to say anything about reality? Peter Hacker, perhaps the most prominent proponent of the traditional interpretation, argues that while the sentences of the Tractatus "fail to comply with the rules of logical grammar-logical syntax", they still succeed in illuminating correct insights about the relation between language and the world. The harmony between the two, necessary for sense, "is shown by the features of our means of representation" (Hacker 2000, 355, 364). For Hacker, this means that "The Tractatus circumscribed the bounds of sense in order to make room for ineffable metaphysics" (Hacker 2001, 164). In other words, "Grammar, or logical syntax, is ineffably justified by reference to the metaphysical structure of the world" (Hacker 1986, 189; see also Hacker 2001, 152-153; Anscombe 1959; Pears 1987).

The traditional interpretation has been criticized by a group of scholars defending the socalled resolute reading of the Tractatus. One of the pivots of the ensuing debate has been the notion of a limit of language. Cora Diamond, James Conant, and others have argued that, instead of putting forth a general theory of meaning that entails such a limit, Wittgenstein aims at showing that there is no limit to our expressive capacities. Accordingly, for the resolute readers, there is no illuminating nonsense envisioned by the traditional interpretation. All nonsense is of the same kind, it is "einfach Unsinn", "mere gibberish" (Diamond 2000, 159; Conant 2002, 424). Hence, given Wittgenstein's statement of the nonsensicality of his own propositions we cannot so much as understand the Tractatus (cf. TLP 6.54). We can only let the book invite us to engage in 
"imaginative activity" of taking its nonsensical sentences as meaningful just to realize how they “dissolve from inside” (Diamond 1991, 158; Goldfarb 1997, 66). Cora Diamond writes: "Are we going to keep the idea that there is something or other in reality that we gesture at, however badly, when we speak of 'the logical form of reality', so that $i t$, what we are gesturing at, is there but cannot be expressed in words? That is what I want to call chickening out." (Diamond 1991, 181.) Juliet Floyd connects the point explicitly to the idea of a limit, writing: "[the Tractatus] conjures up limits over and over again, but only in order to break them, to show them up as false limits" (Floyd 1998, 82; see also Conant 2002, 424). The resolute reading thus denies that Wittgenstein was committed to an idea of limits of language or to the corresponding distinction between saying and showing. Both notions must be thrown away together with the other nonsensical rungs of the ladder comprising the book (Conant 2002, 424; see TLP 6.54).

The obvious motivation for the resolute reading is Wittgenstein's statement about the nonsensicality of the sentences of the Tractatus (TLP 6.54). But there are at least two further reasons for the resolute critique of the traditional interpretation. First, the resolute readers object to the view of the Tractatus as prescribing a fixed logical syntax that would, in turn, limit our thought. They appeal to Wittgenstein's statement: "Frege says that any legitimately constructed proposition must have sense. And I say that any possible proposition is legitimately constructed, and, if it has no sense, that can only be because we have failed to give a meaning to one of its constituents" (TLP 5.4733). The point of this remark, it is argued, is that nonsense results only from our failure to use our words in a meaningful way (Conant 2002, 411-414; Diamond 1991, 196-201). One could object, however, that in the remark in question Wittgenstein talks about possible propositions that are indeed all legitimately constructed. For a proponent of the traditional reading, the potential failure Wittgenstein identifies in the passage is not a failure to think logically. For if a proposition (thought) did not have logical form, it would not be a possible proposition (thought) in the first place (see TLP 3.03, 5.4731). The failure in question is not logical but semantic: the possible 
proposition already has a logical form, but the constituents of the proposition as a formal structure have not (yet) been given meaning (Bedeutung) by being projected onto reality (TLP 3.12-3.13, 4.5; see Hacker 1986, 185).

The idea of logic as a "straightjacket", to borrow Floyd's expression, "a uniquely fixed and explicit system" imprisoning thought and speech, against which the resolute reading has reacted, may be seen as arising from the reception of the Tractatus as a work written primarily in the tradition of Frege and Russell (Floyd 1998, 80-81). Both Frege and Russell were looking for an ideal language cashed out in a Begriffsschrift, a particular syntactic system of analysis. If the Tractatus is read as exclusively reflecting this tradition, then we seem to be left with two options: either Wittgenstein's goal is to formulate such a system in order to limit our expression (as some formulations of the traditional reading suggest) or he outlines such a system only to reject it as nonsensical (as the resolute readers argue). Both readings run into difficulties with the text. The former view is difficult to align with Wittgenstein's claim, often evoked as evidence for the resolute reading, that "all the propositions of our everyday language, just as they stand, are in perfect logical order" (TLP 5.5563). The latter view, in treating the majority of the Tractatus as outright unintelligible, runs the risk of "throwing away the baby together with the bathwater", as Hacker has maintained (Hacker 2000, 369).

However, several commentators have emphasized the difference between the philosophical projects of Wittgenstein on the one hand and Frege and Russell on the other. According to them, Wittgenstein does not aim at the construction of a specific formula language of pure thought, nor does he treat logic as a discipline describing abstract entities, psychological regularities, or the most general truths about reality (TLP 4.0312, 4.441, 5.4; see Kannisto 1986, 81; Glock 1992; 1996a, 203; Glock 1996b, 198-199; McGinn 1999, 502, 508; Moyal-Sharrock 2007, 163; Floyd 2007, 192-210). Instead, "Logic deals with every possibility and all possibilities are its facts" (TLP 
2.0121). Rather than prescribing how one ought to think, logic is concerned with the necessary preconditions for any possible language.

Second, the resolute readers reject the traditional interpretation of logical form as grounded in ontology. For them, "our understanding of possibility is not ontologically based on some realm of the possible, but arises simply from our understanding of and our operating with the sensical sentences of our language" (Goldfarb 1997, 66). The resolute readers are not alone in objecting to the metaphysical interpretation of the foundation of the limits of language either. Commentators such as Peter Sullivan, Marie McGuinn, and Daniele Moyal Sharrock have defended interpretations of the status of logical form as more formal than metaphysical without, however, falling back on the resolute view of the Tractarian sentences as mere gibberish. Sullivan has argued that Wittgenstein rejects both the realist, "object-centered" explanation of the harmony between language and reality as well as its idealist counterpart that locates the necessary form of the world in the subject (Sullivan 1996). McGinn and Moyal-Sharock have emphasized the elucidatory function of the Tractarian sentences as directing our attention to the essential in our language without the need to ground it in something absolute outside of language (McGinn 1999, 2007; Moyal-Sharrock 2007).

Some of the worries raised by the resolute readers and others against the metaphysical interpretation have been addressed also by another, long-established interpretation of the Tractatus that gives further weight to the notion of a limit of language by connecting the term to its arguably Kantian origin. The Kantian interpretation shares the traditional reading's interpretative commitment to what the so-called picture theory requires and implies. But by contrast to the traditional view - and in this particular respect in consonance with the criticisms of the realist reading of the Tractatus - the Kantian interpretation (or at least some variants of it) does not take logical form to answer to an independently established ontological order. The limits of language and of the world are determined by logical form, but this form is taken to be first and foremost the form constitutive of the very possibility of thought. In other words, possibilities of thought are not 
grounded in ontology, but the other way around. As Wittgenstein writes: “A thought contains the possibility of the situation of which it is the thought. What is thinkable is possible too" (TLP 3.02). According to the Kantian interpretation, Wittgenstein's statement that "logic is transcendental" ought to be read in a specifically Kantian sense (TLP 6.13). The logic of the Tractatus resembles Kant's transcendental logic that deals with forms of thought that are at the same time forms of reality and has a role similar to Kant's transcendental, limiting, conditions for the possibility of experience (cf. CPR A57, P 350-365). However, by contrast to Kant, Wittgenstein does not leave any room for synthetic a priori, i.e., for meaningful propositions about states affairs that are true a priori (TLP 2.225; see Stenius 1960, 214; Hacker 1986, 22; Glock 1996a, 132; Glock 1996b, 200). As a condition of sense, logical form is that which makes the truth and falsity of propositions possible. Hence, when Wittgenstein writes that "there is no a priori order of things", the Kantian reading takes him to refer to the contingency of facts expressible by propositions and not to logical form that grounds their possibility (TLP 5.634). This is to say that logic, as a formal condition of thought, is a priori and this is manifest precisely in the impossibility of illogical thought (TLP 5.4731). Moreover, by contrast to what Sullivan calls the "object-centered view" thus referring to the realist interpretation of the limits of language, the Kantian reading emphasizes form also in the case of objects (Sullivan 1996, 207). After all, Wittgenstein claims that objects, as the unalterable substance of the world, are form as well as content (TLP 2.024-2.0271). If this form is primarily the form of thought, as the Kantian reading argues, then the Tractatus's appeal to objects as the substance of the world does not necessarily entail a commitment to an ontologically grounded limit of language. "Empirical reality is limited by the totality of objects", as Wittgenstein writes, but from the transcendental perspective the form of this reality is not independent of the form of thought (TLP 5.5561; see Kannisto 1986, 138-143).

In the Kantian reading, then, the entire project of the Tractatus to draw the limits of meaningful language echoes Kant's project of determining the limits of experience by reflecting the 
transcendental, i.e. necessary and limiting, conditions for their possibility. But this just means that one does not have to run together the notions of an ideal language and that of a limit of language. Ordinary language, just as it is, is already structured by logical form that we know from our own thought. And to realize this means to realize that "The limits of my language mean the limits of my world" (TLP 5.6).

\subsection{Subject as the Limit of the World}

In the Tractatus, the notion of a limit is not used exclusively in relation to logic. Wittgenstein claims that there is a sense in which philosophy can talk about the self that is intimately connected to the limits of language and of the world. The philosophical self in question is not the empirical subject that we encounter among the facts of the world. Indeed, according to Wittgenstein, "there is no such thing as the subject that thinks or entertains ideas" (TLP 5.631). However, the philosophical self surfaces as a limiting condition of the world: "The philosophical self is not the human body, or the human soul, with which psychology deals, but rather the metaphysical subject, the limit of the world - not a part of it" (TLP 5.641, see also 5.632). Hacker has argued that Wittgenstein's conception of the philosophical self resembles the transcendental subject that we find in Kant's and Schopenhauer's philosophy. As pointed out by Hacker, Wittgenstein illustrates the notion in terminology clearly reminiscent of Schopenhauer's writing. The philosophical self is not a Cartesian thinking ego, but rather the subject to whom the world is given. Hence, while everything I experience - i.e., facts of the world - is a posteriori, that my experiences belong to me is a priori. The metaphysical subject is a limit of the world in this precise sense. (Hacker 1986, Ch. 4.)

In the Tractatus, the metaphysical subject has a prominent role in relation to two themes, namely, solipsism and ethics. According to Wittgenstein, the insight that "the limits of my language mean the limits of my world" shows that "what the solipsist means is quite correct; only it cannot be said, but makes itself manifest” (TLP 5.6, 5.62). In Hacker's reading, the route from 
Wittgenstein's conception of language to the solipsist's correct insight reflects the manner in which names, as the constituents of propositions, acquire their meanings. According to Hacker, propositional signs become meaningful only through the speaker's acts of intention. Hence, sense presupposes the metaphysical subject as the subject who means something by the otherwise dead propositional signs or understands them by projecting them into reality (TLP 3.11-3.13; Hacker 1986, 73-80, 100; Hacker 2001, 149). For Hacker, this is the main reason for Wittgenstein's characterization of language as "that language which alone I understand" (TLP 5.62). But if one rejects Hacker's realist interpretation of the Tractatus in favor of the Kantian reading, one could argue further that the solipsist's correct insight has an even more fundamental source. For if the harmony between language and reality is grounded in the necessary form of though, as some proponents of the Kantian interpretation have suggested, then the correctness of transcendental solipsism would readily follow. Language would be "my language" not merely because "by my correlating the components of the picture with the objects, it comes to represent a situation", as Wittgenstein writes in 1914, but also because the other necessary condition for sense, namely, logical form, originates with the metaphysical subject (NB, 33-34; see Kannisto 1986, 124-130).

A completely different take on Wittgenstein's treatment of the metaphysical subject is given in Sullivan's seminal article “'Truth' in Solipsism and Wittgenstein's rejection of the A Priori” (1996). According to Sullivan, Wittgenstein is indeed concerned with transcendental idealism in the passages of the Tractatus that discuss the metaphysical subject (TLP 5.6-5.641). However, Sullivan argues, instead of yielding to the idealist temptation, Wittgenstein aims at disarming the very position along with any substantial notion of a priori. This is not to say that, on Sullivan's account, Wittgenstein was a realist. Rather, Wittgenstein's goal is to find a middle way between the realist and the idealist positions, which both aim at offering a philosophical justification for the harmony between language and the world by grounding it in either ontology or thought. In Sullivan's reading, Wittgenstein's project is not to give any such justification. Instead, 
Sullivan writes, "the notions of language and world which 5.6 begins are the interdependent notions of formal totalities" (Sullivan 1996, 209). Accordingly, we should think of the I as an equally empty, formal notion (ibid., 211).

The other theme closely related to Wittgenstein's notion of a metaphysical subject as the limit of the world is ethics. In the Tractatus, Wittgenstein states that the facts of the world are contingent and therefore lack value (TLP 6.4-6.41). Accordingly, ethics cannot be expressed in language, which is in the business of stating such contingent facts (TLP 6.42). In parallel with his claim about the transcendentality of logic, Wittgenstein writes that "ethics is transcendental" (TLP 6.421). By contrast to logic, the origin of which is wanting conclusive textual evidence and subject to scholarly debate, ethics is, at least in the Notebooks 1916, explicitly claimed to "only enter through the subject" (NB 79). In the Notebooks, Wittgenstein writes that while a thinking subject is an illusion, the willing subject is not (NB 80). Moreover, the will in question is good or evil (NB 80; see NB 73, 76). In Wittgenstein's account, the world is independent of the will, but this does not render ethics illusory (TLP 6.373, 5.1362). While deprived of the ability to influence the facts of the world, the willing subject can alter its limits: "If the good and the bad exercise of the will does alter the world, it can alter only the limits of the world, not the facts - not what can be expressed by means of language" (TLP 6.43).

In his remarks on ethics, Wittgenstein is again digressing the bounds of meaningful language as dictated by the Tractatus (TLP 6.373-6.522). While the traditional interpretation has been inclined to question whether Wittgenstein's remarks on value coherently fit into the broader framework of the Tractatus, the resolute reading has stressed the ethical import of the Tractatus, but independently of the internal evidence provided by the Tractatus (Hacker 1986, 105; Conant 2005, 69-70). In contrast to both, the Kantian interpretation has stressed the fact that the notions evoked by Wittgenstein in this context are the very same notions that for Kant lie outside the bounds of experience, as they arise either from practical reason or from the reflective use of the power of 
judgment. These notions include ethics, aesthetics, will, freedom, God, immortality of the soul, and religious faith, and the world as a whole (TLP 6.373-6.45; see Stenius 1960, 222; Moore 1987; Moore 2013, 251-253; Moore 2007, 184-187). For Wittgenstein, these notions comprise the "mystical" that lies beyond the limits of meaningful language.

Again, the difference between Kant and Wittgenstein results from Kant's view that, while we cannot have knowledge of free will, God, or eternity, and while attempts to establish claims to such knowledge will only lead to dogmatic metaphysics, reason can form expressible thoughts of such notions even if these do not correspond to anything in empirical reality. By contrast, for the early Wittgenstein, who limits meaningful language and thought to propositions about the contingent facts of empirical reality, the aforementioned notions must be "passed over in silence" (TLP 7; see Stenius 1960, 218). Nevertheless, in accordance with Kant, whose motivation to draw the limits of experience by reflecting their necessary, transcendental conditions was to "make room for faith" (CPR BXXX), Wittgenstein, too, claims to draw the limits of language to safeguard value. He writes to Ludwig von Ficker: "the point of the book is ethical. [...] I wanted to write that my book consists of two parts: one of which is here, and of everything which I have not written. And precisely this second part is the important one. For the Ethical is delimited from within, as it were by my book; and I'm convinced that, strictly speaking, it can ONLY be delimited in this way." (Luckhardt 1979, 94-95.)

\section{The Later Views}

In 1931, Wittgenstein connects the idea of a limit of language explicitly to the Kantian tradition. He writes: "The limit of language manifests itself in the impossibility of describing the fact that corresponds to (is the translation of) a sentence without simply repeating the sentence. (We are involved here with the Kantian solution of the problem of philosophy.)" (CV, 13). Wittgenstein is already distancing himself from some of the central commitments of the Tractarian view, but these 
words still echo the idea of logic as the inexpressible condition of sense. While every possible fact is expressible in language, we cannot step above our language to describe its formal correspondence with the world in "another language dealing with the structure of the first language", as Russell in his Introduction to the Tractatus had - to Wittgenstein's annoyance - suggested (TLP, xxii).

Nevertheless, by the 1930s Wittgenstein's early conception of language as a unified totality, limited by an immutable logical form and crystallized in the notion of a general propositional form that every meaningful proposition must meet, has become the target of Wittgenstein's criticism (TLP 4.001, 4.5, 5.471, 5.4711; cf. PI §23-24, 108, 114). In 1930 Wittgenstein states, still echoing the Tractatus: "What sort of harmony must there be between thoughts \& the world? Only that the thought must have logical form; \& without this it wouldn't be a thought." (M, 4:18.) But now he adds: "What language must have in common is contained in rules of grammar" (M, 4:18). By contrast to the logical form of the Tractatus, grammar involves elements that are not purely syntactical, but incorporate features that at the outset look empirical. Moreover, the rules of grammar are not immutable, but they may be abandoned, provided that we are willing to give up the use they have made possible: "What I say of grammar (including inference) is always arbitrary rules: they needn't be used, but if we change them, we can't use them in this way" (M, 5:88). So even as arbitrary rules, the rules of grammar make the use of language possible.

Wittgenstein also discards the Tractarian assumption of simple objects as the termini of logical analysis and (arguably) grounding the logical form of the world (TLP 2.022). This idea, he now claims, was a digression into thinking along the lines of empirical science - a philosophical confusion that he himself had warned against (M, 5:30, 7:39, 7:88, 7:92; cf. TLP 4.111).

Wittgenstein states repeatedly that the rules of grammar are arbitrary or autonomous, not answering to anything over and above grammar itself (see e.g. M, 5:87, 5:91, 6:34). Yet, in accord with the Tractatus, according to which "logic must look after itself", Wittgenstein still claims that the rules of grammar cannot be justified (TLP 5.473; M, 5:87). According to him, "To rules of translation 
from language into reality correspond rules of grammar: \& there is no possible justification for these: because any language by which we could try to justify would have to have a grammar itself: no description of world can justify rules of grammar" (M, 5:54). Moreover, Wittgenstein connects the point at which justifications have been exhausted to the limit of language. He says: "Philosophy may expect to arrive at fundamental propositions. But great event to which we come is the coming to the boundary of language: there we can't ask anything further" (M, 5:28). Wittgenstein suggests that grammatical systems may be approached either "discursively", i.e., as calculi that may be taught to another, or "intuitively", i.e., "taking something in as a whole at a glance" (M, 8:59). This latter perspective that "overlooks" (überseht) a grammatical system as a whole limited by its constitutive rules may be seen as precursor of Wittgenstein's mature conception of the philosophical method as one that provides "surveyable representations" (übersichtliche Darstellung) of grammar (M, 9:33, 9:38; PI §122).

As these examples from the 1930s serve to show, Wittgenstein's rejection of central elements of his early account does not mean that the notion of a limit disappears from his imagery. Instead, it is appropriated to the new idea of grammatical systems, and later, in the Philosophical Investigations, to his mature treatment of concepts and language-games. Given Wittgenstein's increasingly flexible conception of grammar, the boundaries he talks about become equally flexible. Nevertheless, even in Wittgenstein's later philosophy, the idea of a limit of language is connected to themes that figure in the Tractatus as that which transcends the empirical. Such themes include grammar, the practice of philosophy, aesthetics, and religion. Of ethics, the later Wittgenstein remains more or less silent, except for his 1933 remark, reminiscent of the Tractatus's equation between ethics and aesthetics: "Practically everything I say of 'beautiful' applies in a slightly different way to 'good"' (M, 9:18).

According to the traditional interpretation of Wittgenstein's mature philosophy, the key goal of the Philosophical Investigations is to provide an account of language as a family of games, 
each constituted by their respective sets of grammatical rules (PI §104). The meaning of a word should not be understood as an object the name stands for, but is best characterized as the word's use in the context of a language-game (PI §43). The point of using the word "language-game", Wittgenstein writes, is to "emphasize the fact that the speaking of language is part of an activity, or of a form of life" (PI §23). The rules of language are thus not fixed or tabulated into a manual, but given in the practice of using language and transmitted by training and examples (PI §§198-199, 208-210, 355). Moreover, as the rules of language are to be found in the "customs, uses, and institutions" of a linguistic community, they are subject to change and cultural variation (PI §199). Accordingly, the idea of a limit of language becomes more flexible, historically changing, and indefinite: a riverbed ever changing with the fluctuation of water rather than a fence set up once and for all (see OC §§97-99). Wittgenstein also points out that when a limit is drawn, it is drawn for a particular purpose. Discussing the limits of concepts, Wittgenstein writes: "For I can give the concept 'number' rigid limits in this way, that is, use the word 'number' for a rigidly limited concept, but I can also use it so that the extension of the concept is not closed by frontier. And this is how we do use the word "game". For how is the concept game bounded? What still counts as a game and what no longer does? Can you give it a boundary? No. You can draw one; for none has so far been drawn. (But that never troubled you when you used the word 'game'.)" (PI §68). Words are meaningful as long as they have a use in our language, and that use does not have to be fixed in advance by strict boundaries formulated by means of necessary and sufficient conditions.

In spite his new emphasis on linguistic practices and the human form of life, the later Wittgenstein still adheres to the distinction between the empirical and the grammatical (TLP 3.33, $5.552,6.111$; PI $\S \S 90,109,251,295,458)$. While the notions of truth and falsity apply to empirical statements and opinions, they do not apply to grammar. Rather, we take the grammatical for granted in our use of language. Indeed, it is this taking-for-granted that makes the truth and falsity of empirical propositions possible (PI $\S 240-241$, 482; see McGinn 1999, 502, 512; Moyal-Sharrock 
2007, 157). It is important to notice that, by contrast to Wittgenstein's early conception of logical form to be uncovered by analysis, the status of the grammatical as necessary does not arise from a source independent of our use of language. It is the way in which certain propositions are actually used in our language, their role in our language, that gives grammatical propositions their status as necessities: "To accept a proposition as unshakably certain - I want to say - means to use it as a grammatical rule: this removes uncertainty from it" (RFM III: 39). Moreover, the status of a given proposition as either empirical or grammatical may change based on its use. As Hans-Johann Glock notes, "we can remove a sentence from the scope of empirical refutation by using it normatively rather than descriptively" (Glock 1996b, 208). This is not to say that grammar is matter of mere opinion. Wittgenstein himself makes the point explicitly by writing: "So are you saying that human agreement decided what is true and what is false?' - It is what human beings say that is true and false; and they agree in the language they use. That is not agreement in opinions but in form of life.” (PI §241). Without such basic agreement, taken for granted in our use of language, the possibility of making true and false statements would evaporate.

In spite of drawing their status as necessities from our use, grammatical rules provide the criteria by which we distinguish between correct and incorrect uses of words and, accordingly, between understanding and misunderstanding. The understanding of words and sentences is the ability to follow the rules constitutive of their use, manifest in the speaker's ability to justify her linguistic usages by appeal to the rules (PI $\S 185-242)$. It is not yet enough that my behavior conforms to the rule that is constitutive of the game providing the context of the use. If I understand, then my behavior ought to be internally related to the rule so that, for example, I can appeal to the rule in explaining my application thereof. The rule is, as the traditional interpretation given in Peter Hacker's and Gordon Baker's commentary puts it, “involved in [my] activity as a reason or part of a reason for acting thus-and-so" (Baker and Hacker 2009, 138). If this were not the case, then it would make no sense to talk about understanding, which after all is a normative notion 
standing in need of a criterion to distinguish it from misunderstanding. However, Wittgenstein states repeatedly that reasons come to an end. That "once I have exhausted the justifications, I have reached bedrock, and my spade is turned. Then I am inclined to say: 'This is simply what I do'.' (PI §217.) Here, we meet the limit of language again in the form of the bedrock that stops the chain of justification. Wittgenstein writes: "A reason can only be given within a game. The links of a chain of reasons come to an end, at the boundary of the game" (PG, 97; see also PI $\S \S 326,482,485)$. At the boundary of the game there is no further justification to be found, nor any room to meaningfully question whether one ought to follow these rules. Instead, "when I follow the rule, I do not choose. I follow the rule blindly" (PI §219).

What Wittgenstein means by the bedrock and the notion of blind rule-following has been a topic of intense scholarly discussion. As in the case of the Tractatus, the main points of disagreement concern the ways in which the notion of grammar and the nature of philosophy in Wittgenstein's later philosophy ought to be understood. Some commentators object to the traditional, “normativist” or rule-based interpretation of Wittgenstein's later philosophy just outlined. An early critic of Wittgenstein's emphasis on rules and games was Rush Rhees, who took Wittgenstein game analogy to be giving a misleading view about the nature of human communication (Rhees 1959-1960, 182). Later, proponents of the "resolute" or "therapeutic" interpretation have argued that it is in fact a mistake to attribute a rule-based account of language to Wittgenstein himself as well. Rule-bound games may be useful objects of comparison for language, to be used in "piecemeal treatment" of philosophical problems, but to take Wittgenstein to be advocating a rule-based conception of language is to fall guilty of philosophical dogmatism against which Wittgenstein warned (Kuusela 2008; Conant 2011). According to the therapeutic reading, the traditional reading mistakenly takes the philosopher's job to be to "police the borders between sense and nonsense" by tabulating rules of grammar (Morris 2006, 1). Instead, it is argued, the goals of Wittgenstein's later method are closer to psychotherapy that aims at dissolving individual 
confusions without any generally valid philosophical arguments or claims (Baker 2006, 109-118, 205-222).

But to align the anti-normativist interpretation with Wittgenstein's undeniable focus on rules is difficult. Wittgenstein writes in the Philosophical Investigations that "If rule became exception, and exception rule; or if both became phenomena of roughly equal frequency - our normal language-games would thereby lose their point” (PI §142). And even more emphatically in manuscript 164: "Following according to the rule is FUNDAMENTAL to our language-game. It characterizes what we call description" (RFM, VI-28). Rather than indicating a contrast between the descriptive approach in philosophy and the notion of a rule, these remarks suggest that Wittgenstein himself took description and rules to belong together. What is to be described, for a particular philosophical purpose, is a language-game, a rule-governed structure among other structures that together comprise our language (PI §108). Besides, what is sometimes highlighted as the distinctive feature of Wittgenstein's later philosophy, namely, its critical stance towards philosophical theories, is a methodological commitment present already in the Tractatus (TLP 4.112, PI § 109).

The necessity of taking something for granted in order to think meaningfully becomes particularly dominant in Wittgenstein's latest work, published in On Certainty. Here, Wittgenstein's treatment of "certainties", propositions that we treat as immune to doubt, broadens the notion of grammatical rules to cover sentences that express basic certainties of our world-view. Such basic certainties include assurance of matters that G. E. Moore treated as knowledge, for example, that "I have two hands". Wittgenstein does not accept Moore's position, given that he takes knowledge to presuppose the possibility of justification, missing in the case of basic certainties where neither doubt nor the demand of justification arises. Rather, the possibility of justifying non-basic beliefs (empirical beliefs and everyday opinions) as well as the possibility of false beliefs is grounded in our taking for granted certainties that themselves are ungrounded (see e.g. OC $\S \S 94-95,105,136$ ). According to Danièle Moyal-Sharrock, we ought to understand grammatical rules, including 
formulations of our basic certainties, as nonsense. Given that grammatical rules have no use within the bounds of a language-game, "they have no sense; they determine sense" (Moyal-Sharrock 2017, 558). In this respect, the "hinge propositions" discussed in On Certainty may be seen as successors of the sentences of the Tractatus: both are useless in language, as "their only use is to delineate and elucidate the correct use of language" (Moyal-Sharrock 2007, 170). Accordingly, to doubt basic certainties is "logically impossible" and amounts to "having lost the bounds of sense" (OC $\$ 454$; Moyal-Sharrock 2017, 549). While we can formulate a grammatical rule for philosophical purposes, in the actual use of language they say nothing. This is why Wittgenstein writes: “"There are physical objects' is nonsense" (OC §35).

In the Tractatus, the task of philosophy was one of drawing the limits of language to demarcate sense from nonsense. In the Philosophical Investigations, Wittgenstein writes that the task of the philosopher is to describe language games, i.e., practice-laden ways of using language, without explaining or justifying them in any way (PI $\S 109,124-129)$. The descriptive approach does not render philosophical investigation empirical, because what directs the description is a philosophical problem. Instead of phenomena, philosophical investigation is, as Wittgenstein writes, "directed towards the possibilities of phenomena" (PI §90, cf. TLP 2.0121). This is what makes the investigation grammatical rather than empirical (PI §187). Again, Wittgenstein connects the practice of philosophy understood as grammatical investigation to the limits of language: "The results of philosophy are the discovery of some piece of plain nonsense and the bumps that the understanding has got by running up against the limit of language. They - these bumps - make us see the value of that discovery" (PI §119). But while the mature Wittgenstein still treats the limits of grammar as that which excludes nonsense, he now emphasizes that such limits are always drawn for a particular purpose: “To say 'This combination of words has no sense' excludes it from the sphere of language, and thereby bounds the domain of language. But when one draws a boundary, it may be for various kinds of reasons.” (PI §499.) 
In Wittgenstein's later view, then, the limits of language are reached at the boundary of a language-game, where justifications made possible by the rules constitutive of that game have been exhausted and we simply take the rules themselves for granted. At this boundary or bedrock, we can only act or else, for purposes of philosophical clarification, describe the game in question (PI §261). Particularly poignant cases of reasons coming to an end surface in Wittgenstein's later discussions of religion and aesthetics. In his lectures on aesthetics and religious belief, Wittgenstein focuses on cases where one cannot convince one's interlocutor by appeal to explicit rule-formulations. While aesthetic judgments call for reasons, the kind of reason-giving we find in aesthetics takes the form of comparisons between a particular aesthetic choice and something else, intended to guide the interlocutor to see the aesthetic phenomenon from a particular perspective. But this just means that I cannot force another to adopt my judgment by arguments: "If when I've made you see what I see, it doesn't appeal to you, there is an end" (M, 9:31).

We find a similar end in reason-giving in Wittgenstein's later discussion of religious belief. One might expect Wittgenstein to emphasize the role of the linguistic community and tradition for the possibility of religious language, given the importance placed on the linguistic community and the human form of life in his later thought. But interestingly, in his lectures on religious belief Wittgenstein discusses a gulf that may appear between a religious person and himself as somebody who does not share the "pictures" that lay down the foundation for the believer's world view (LC, 55). According to Wittgenstein, it is impossible for him to contradict the person, as he might in cases of ordinary empirical disagreements $(\mathrm{LC}, 55)$. Whether this means that the believer and the non-religious person "play different language-games", each limited by their own rules and hence not allowing for a translation, has been subject to debate. Those drawing on the legacy of Rush Rhees have emphasized that in spite of Wittgenstein's spatial metaphor, suggesting an unbridgeable gap between different language-games, "levels", or "planes" the disputants inhabit, the nonreligious person may reasonably criticize the religious claims (Diamond 2005). Others, influenced 
by the more traditional interpretation have taken Wittgenstein to argue religious beliefs are "immune from falsification and from verification" and in this respect on a par with grammatical rules (Hyman 2001, 7; see Schroeder 2007, 443-445, 459; Pritchard 2018).

\section{The Form and Content of This Volume}

This collection brings together twelve articles that approach Wittgenstein's notion of the limits of language from a variety of perspectives. With the exception of A. W. Moore's article, "The Bounds of Nonsense", which has been published in Moore's volume Language, World, and Limits: Essays in the Philosophy of Language and Metaphysics (OUP, 2019), all articles have been newly commissioned. Part I, Logic, Self, and Value in Wittgenstein's Early Philosophy, consists of three chapters that address the notion of a limit in the three roles assigned to it in the Tractatus: logic, the philosophical self, and ethics as limits of language and of the world. Part II, Grammar, Linguistic Community, and Value in Wittgenstein's Later Philosophy, follows the same overall pattern. It begins with four different interpretations of Wittgenstein's later treatment of the limits of language, continues to two contributions reflecting the potential limitations that arise from our anthropocentric perspective, and closes with three articles that address themes that Wittgenstein associates with the limit of language throughout his career, namely, religion, aesthetics, and ethics.

In his article "The Bound of Nonsense", A. W. Moore examines the distinction between sense and nonsense in the Tractatus. He begins by addressing Cora Diamond's and Michael Kremer's denial of the view that, according to the Tractatus, all pseudo-propositions are nonsensical. Noting that such a denial, in exempting certain pseudo-propositions from the charge of nonsensicality, could exacerbate the mystery of why the pseudo-propositions in the Tractatus are not among those to be exempted, Moore proceeds to introduce what he calls the Principal Distinction. This is the distinction, undeniably fundamental for the project of the Tractatus, between truth-valued propositions (including tautologies and contradictions) and truth-valueless 
pseudo-propositions. Moore argues that, for Wittgenstein, our understanding of what it is for something to be a truth-valueless pseudo-proposition is not independent of our understanding of the notion of a proposition with a truth-value. Rather, a pseudo-proposition without a truth-value is an item that has the false appearance of being a proposition with a truth-value. The article closes with an appendix, comparing the Tractatus's truth-valueless pseudo-propositions with Kant's idea of an "empty thought", indicating an interesting parallel but also an important contrast between the two.

In his article "Solipsism and the Graspability of Fact", Colin Johnston sets out to provide an answer to the hard question of what Wittgenstein means by stating that "the limits of my language are the limits of my world" (TLP 5.6). His argument begins by suggesting that the Tractarian conception of a fact is essentially Fregean: as in Frege, truth's "pride of place" dictates that a fact is at base a possible truth. This suggestion is subsequently justified by means of a thought that the subject makes no sense of content to her thinking going beyond in kind that of a truth or falsehood. This thought further includes, however, that truth is not something independent of graspability or possessability by me, a point which threatens an idealism. This threat is deflected, however, by recognising that the "me", i.e. the subject in question, has no content or character: there is no way of making a contrast between the subject's world and what lies outside of it, no way for the subject to find content independent of herself and accordingly content to herself.

The third article on Wittgenstein's early philosophy, written jointly by Hanne Appelqvist and Panu-Matti Pöykkö, discusses Wittgenstein's early ethics by comparing it with Emmanuel Levinas's ethical thought. Both Wittgenstein and Levinas claim ethics to be a "condition of the world", not explicable by reference to the empirical facts of the world (NB, 77; Levinas 1969, 204, 212). The authors argue that what motivates Wittgenstein's and Levinas's respective accounts is the characteristically Kantian contrast they identify between the absolute ethical demand on the one hand and the contingency of the facts of the world on the other. As any substantial ethical theses would only render ethics conditional, the task of the philosopher is to reflect on the transcendental 
grounds of the ethical demand. In this respect, the writers argue, both Wittgenstein and Levinas ought to be read as belonging to the Kantian tradition. After indicating the analogous ways in which both Wittgenstein and Levinas make use of the Kantian framework, the article explores the main difference between the two: while Wittgenstein's early ethics is grounded in an aesthetic, contemplative perspective on the world as a whole, Levinas famously takes the other person to be constitutive for the ethical perspective.

William Child's article “"We can go no further”: Meaning, Use, and the Limits of Language" examines the limit of language as it appears in Wittgenstein's later philosophy. Child's point of origin is Wittgenstein's later statement about the impossibility of getting outside of language by means of language, which marks an important continuity with the views of the Tractatus. In Wittgenstein's later work, the idea is manifest in his denial of the possibility of general metaphysical theses about reality, of providing a linguistic characterization of the relation between language and the language-independent world, and of the possibility of teaching the use of language by means of explanations to someone who does not already master a language. Connecting these points to the debate between reductionism and anti-reductionism about meaning and rules, Child asks whether it is possible to give a substantive and non-circular explanation of what it is for someone to follow a particular rule. He argues that, while Wittgenstein ought to be read as an anti-reductionist about meaning, his point about meaning as use is not a mere pleonasm. Instead, Child argues, Wittgenstein's position entitles us to demand some account of the relation between semantic and non-semantic facts. According to Child, this relation is one of supervenience - an interpretation he substantiates by a detailed analysis of Wittgenstein's arguments presented in the Remarks on the Foundations of Mathematics and the Brown Book.

Leila Haaparanta's article "Frege, Carnap, and the Limits of Asserting" explores the broader philosophical context of the notion of a limit of language by relating the historical positions of Frege and Carnap to current debates on assertion. Referring to the distinction between logic as 
language and logic as calculus, Haaparanta argues that while Frege's conceptual notation is a calculus (in Frege's own sense of the term), it is also intended as a universal language: everything that can be thought can be also be expressed in that notation. Moreover, like Wittgenstein's early denial of the possibility of overcoming logical form in language, Frege's conceptual notation does not allow for a metaperpective from which to compare language with the world. Paying attention to Frege's discussion on different ways of justifying assertions, Haaparanta then raises the question of the legitimacy of philosophical assertions. While Frege's texts do not settle the question, in Carnap's "Empiricism, Semantics, and Ontology" we find a classic example of an argument that denies the possibility of metaphysical assertions by appeal to a kind of limit of language, namely, Carnap's notion of a linguistic framework and his distinction between statements internal and external to that framework. Haaparanta's article closes by proposing that Carnap's discussion of the nature of external propositions may be used as an informative point of comparison for Wittgenstein's later remarks on philosophy and philosophical assertions.

Paul Standish's article “On Being Resolute” addresses the notion of a limit of language against the background of the debate between resolute and traditional interpretations of Wittgenstein's thought. Here, the traditional interpretation is understood as putting forth a narrative of the early Wittgenstein as an advocate of a realist truth-conditional theory of meaning to be replaced by Wittgenstein's later, anti-realist theory of meaning given by assertability-conditions. Such a story, it is argued, not only fails to capture elements of continuity of Wittgenstein thought, but commits the early and the later Wittgenstein to the metaphysical assumption of a possibility of stepping outside of language. In doing so the traditional view "represent[s] the matter as if there were something one couldn't do", thus dismissing Wittgenstein's explicit warning against doing just that (PI §374). Rather than taking an explicit stance on the debate, Standish considers the inevitability of the urge to overcome the limits as well as the difficulty of returning to the ordinary, promised to serve as the cure to the urge. He does this by comparing the work of Wittgenstein and 
Heidegger in light of Stanley Cavell's work, the comparison leading to the acknowledgement of limits of language and of the restlessness of the desire to exceed them.

Yrsa Neuman's article "Moore's Paradox and the Limits of Language Use” discusses Wittgenstein's treatment of G. E. Moore's paradox, namely, the absurdity involved in the utterance "It is raining, but I do not believe that it is raining". Wittgenstein's initial response to the paradox consists in conceptual clarification of the grammatical landscapes of belief and first-person and second-person ascription and expression, intended to uncover the assumptions underlying the paradox. While some of these assumptions seem to indicate the limits of language use, Neuman's discussion shows that instead of aiming to establish or unveil rules of language to rule out the Moorean sentence, Wittgenstein's approach is sensitive to particular cases that may not follow the ordinary pattern of language use. Neuman sees this as a central feature of Wittgenstein's method, and argues that Moore's paradox emerges only when language is approached from the "cold" philosophical viewpoint without an actual context; and once a context is provided, there is nothing paradoxical about it. Accordingly, she suggests, what needs to be explained is not why the Moorean sentence fails, but our urge to philosophize about a mere piece of surface grammar.

If for the early Wittgenstein the subject of language is a formal I, the later Wittgenstein turns to the linguistic community as the subject of language. Sandis's article "Who are 'we' for Wittgenstein?" asks how we ought to understand Wittgenstein's frequent references to "us". Who are we who practice philosophy, who could not understand a lion if it spoke, and whose form of life finds expression in language? Sandis addresses such questions by examining Wittgenstein's later usages of "we" and its cognates. According to his analysis, the term sometimes refers to the community of philosophers, while at other times it is intended to point to language users, to average people, or a specific cultural community. Such groups ought to be contrasted, not just with that of all humans in a general sense, but also with a transcendental "we", as evoked by those interpretations that read the later Wittgenstein as a linguistic idealist. 
Hans-Johann Glock’s article “Animal Consciousness - a Limit of Language” discusses phenomenal consciousness, which is often deemed a mysterious phenomenon defying naturalistic explanation or even conceptual comprehension. Arguing against the corresponding two variants of the orthodox view, which he calls (new) mysterianism and (neo-) mysticism respectively, Glock defends a deflationist account of consciousness. Drawing in part on Wittgenstein's later discussion on mental phenomena and private language, Glock argues that the sense of a mystery that the orthodox positions attribute to phenomenal consciousness does not mark a genuine limit either of knowledge or of language but rather results from conceptual confusions. Glock develops his argument by discussing the consciousness of non-human animals, thus addressing Ernst Nagel's question "what it it like to be a bat?". According to Glock, Nagel's question can in fact be answered in an informative and reasonable way by reference to empirical findings concerning the behavioural capacities, life form, and environment of bats. The real challenge related to consciousness does not pertain to qualia, Glock argues, but to the grounds of attributing intentional states to animals. For while it is perfectly possible to ascribe some intentional states to animals based on our knowledge of animals and their behavior, there is indeed a limit to such ascriptions, namely of determining the precise content of more complex intentional states. However, rather than pointing to ineffable animal intentionality, this limit is imposed by our undeniably anthropocentric language as applied to creatures that do not talk.

Pihlström's article “The Limits of Language in Wittgensteinian Philosophy of Religion” discusses the nature of religious language and belief and the way in which philosophers influenced by Wittgenstein's work, most notably D. Z. Phillips, have approached the theme. Noting the uneasiness with which the Wittgenstein tradition of philosophy of religion has regarded the metaphor of a limit in Wittgenstein's writing, Pihlström argues that instead of disarming the notion of a limit, we ought to take it as pointing to the Kantian undertones of Wittgenstein's philosophy. Indeed, he suggests, some of the arguments put forth in the Wittgensteinian tradition of philosophy 
of religion could be read as transcendental arguments. While religious language is not based on empirical evidence, it is still conditioned by the concrete circumstances of our lives and makes possible a response to actual human suffering. Considering the problem of evil and the way in which it has been treated in the Wittgensteinian tradition, Pihlström argues that Wittgenstein's remarks on religion provide resources for formulating a transcendental version of antitheodicy.

Guter’s article “Measure for Measure: Wittgenstein's Critique of the Augustinian Picture of Music" discusses Wittgenstein's later remarks on music, connecting them to Wittgenstein's distinction between memory-time and information-time in his middle period. Guter argues that Wittgenstein's emphasis on public information-time as that which conditions or circumscribes memory-time sets his conception of musical expression apart from the philosophical tradition that originates in Augustine's discussion of time. Insofar as our utterances about musical experiences geared toward the order of memory-time are meaningful, they must rely the framework of our ordinary language and its order of information-time. Guter's discussion brings to surface the particularity of expression and the aesthetically "right" in music, evoked by Wittgenstein's remarks on simultaneity and tempo in music and language. According to Guter, the musical practice and its collaborative quest for drawing in significance by means of the phrasing and re-phrasing of a musical passage to characterize it, ultimately enables distinctions between aesthetic right and wrong.

The collection closes with Danièle Moyal-Sharrock's article "Literature as the Measure of our Lives", which discusses the relation between literary language and reality, thereby engaging with the debate on realism and idealism in Wittgenstein later thought. Moyal-Sharrock stresses the reality-soakedness of language, and argues that its being impacted by the extra-linguistic makes language both a vital and an autonomous force. She argues that Wittgenstein's remarks on literature speak to the inseparability of form and content in literature. She takes her clue in Wittgenstein to argue that the language of literature does not belong to the veridical domain of discursive language 
but provides a qualitatively different and invaluable perspective on our lives by showing what cannot be said. That is, how we use language aesthetically to evoke what cannot be described or referred to veridically, and yet deeply generates or enhances moral and psychological understanding. In indicating how the distinction between saying and showing is reflected in Wittgenstein's later discussion of poetry and literature, Moyal-Sharrock's argument traces an important continuity between Wittgenstein's early and later views.

\section{References}

Anscombe, Elizabeth (1959) An Introduction to Wittgenstein's Tractatus. London: Hutchinson University library.

Baker, Gordon (2006) Wittgenstein's Method: Neglected Aspects. Oxford: Blackwell.

Baker, Gordon and Peter Hacker (2009) Wittgenstein: Rules, Grammar and Necessity, Volume 2 of An Analytical Commentary on the Philosophical Investigations. Oxford: Blackwell.

Conant, James (2002) “The Method of the Tractatus" in Erich H. Reck, ed., From Frege to Wittgenstein: Perspectives on Early Analytic Philosophy, 374-462.

Conant, James (2005) "What 'Ethics' in the Tractatus is Not" in D. Z. Phillips \& Mario von der Ruhr, eds., Religion and Wittgenstein's Legacy. Aldershot: Ashgate, 
Conant, James (2011) "Wittgenstein's Methods" in Oskari Kuusela and Marie McGinn, eds., The Oxford Handbook of Wittgenstein. Oxford: Oxford University Press, 620-645.

Diamond, Cora (1991) The Realistic Spirit. Cambridge, Mass.: MIT Press.

Diamond, Cora (2000) “Ethics, Imagination, and the Method of Wittgenstein's Tractatus" in Alice Crary and Rupert read, eds., The New Wittgenstein. London: Routledge, 149-173.

Diamond, Cora (2005) “Wittgenstein on Religious Belief: The Gulfs Between Us”, in D. Z. Phillips \& Mario von der Ruhr, eds., Religion and Wittgenstein's Legacy. Aldershot: Ashgate, 99-137.

Floyd, Juliet (1998) “The Uncaptive Eye: Solipsism in Wittgenstein's Tractatus”, in Leroy S. Rouner, ed.. Boston Studies in Philosophy of Religion, Vol 19, Loneliness. Notre Dame, Ind.: University of Notre Dame Press, 79-108.

Floyd, Juliet (2007) "Wittgenstein and the Inexpressible", in Alice Crary, ed., Wittgenstein and the Moral Life: Essays in Honor of Cora Diamond. Cambridge, Mass.: MIT Press, 177-234.

Glock, Hans-Johann (1992) "Cambridge, Jena or Vienna? The Roots of the Tractatus", Ratio 5 (1), $1-23$.

Glock, Hans-Johann (1996a) The Wittgenstein Dictionary. Oxford: Blackwell.

Glock, Hans-Johann (1996b) "Necessity and Normativity”, in Hans D. Sluga and David Stern, eds., The Cambridge Companion to Wittgenstein. Cambridge: Cambridge University Press, 198-225. 
Goldfarb, Warren (1997) "Metaphysics and Nonsense: On Cora Diamond's The Realistic Spirit”, Journal of Philosophical Research 22, 57-73.

Hacker, Peter (1986) Insight and Illusion. Revised edition. Oxford: Clarendon Press.

Hacker, Peter (2000) “Was He Trying to Whistle It?”, reprinted in Peter Hacker, Wittgenstein: Connections and Controversies. Oxford: Oxford University Press, 98-140.

Hacker, Peter (2001) "When the Whistling had to Stop" reprinted in Peter Hacker, Wittgenstein: Connections and Controversies. Oxford: Oxford University Press, 140-169.

Kannisto, Heikki (1986) Thoughts and Their Subject: A Study of Wittgenstein's Tractatus. Acta Philosophica Fennica 40.

Kuusela, Oskari (2008) The Struggle against Dogmatism: Wittgenstein and the Concept of Philosophy. Cambridge, Mass.: Harvard University Press.

McGinn, Marie (1999) “Between Metaphysics and Nonsense: Elucidation in Wittgenstein's Tractatus", The Philosophical Quarterly 49 (197), 491-513.

Moore, A. W. (1987) “Beauty in the Transcendental Idealism of Kant and Wittgenstein”, British Journal of Aesthetics 27 (2), 129-137. 
Moore, A.W. (2007) “Wittgenstein and Transcendental Idealism”, in Guy Kahane, Edward Kanterian, and Oskari Kuusela, eds., Wittgenstein and His Interpreters. Oxford: Blackwell, 174199.

Moore, A.W. (2013) "Was the Author of the Tractatus a transcendental idealist?", in Peter Sullivan and Michael Potter, eds., Wittgenstein's Tractatus: History and Interpretation. Oxford: Oxford University Press, 239-255.

Morris, Catherine (2006) Introduction in Gordon Baker, Wittgenstein's Method: Neglected Aspects. Oxford: Blackwell, 1-18.

Moyal-Sharrock, Danièle (2007) “The Good Sense of Nonsense: a Reading of Wittgenstein's Tractatus as nonself-repudiating”, Philosophy 82, 147-177.

Moyal-Sharrock, Danièle (2017) “Wittgenstein on Knowledge and Certainty”, in Hans-Johann Glock and John Hyman, eds., A Companion to Wittgenstein. Oxford: Wiley-Blackwell, 547-562.

Pears, David (1987) The False Prison Vol I. Oxford: Clarendon Press.

Rhees, Rush (1959-1960) “Wittgenstein's Builders.” Proceedings of the Aristotelian Society 60, $171-186$.

Hyman, John (2001) “The Gospel according to Wittgenstein”, in R. L. Arrington \& M. Addis (eds) Wittgenstein and Philosophy of Religion. London: Routledge, 1-11. 
Kannisto, Heikki (1986) Thoughts and Their Subject: A Study of Wittgenstein's Tractatus. Acta Philosophica Fennica Vol 40. Helsinki: The Philosophical Society of Finland.

Kant, Immanuel (1998) Critique of Pure Reason (CPR). Translated and edited by Paul Guyer and Allen Wood. Cambridge: Cambridge University Press.

Kant, Immanuel (2004) Prolegomena to Any Future Metaphysics (P). Translated and edited by Gary Hatfield. Cambridge: Cambridge University Press.

Levinas, Emmanuel (1969) Totality and Infinity. Translated by A. Lingis. Pittsburgh: Duquesne University Press.

Pritchard, Duncan (2018) “Quasi-Fideism and Religious Conviction”, European Journal for Philosophy of Religion 10 (3), 51-66.

Schroeder, Severin (2007) “The Tightrope Walker”. Ratio (new series), 20 (4), 442-463.

Stenius, Erik (1960) Wittgenstein's Tractatus: A Critical Study of its Main Lines of Thought. Oxford: Basil Blackwell.

Sullivan, Peter (1996) “The 'Truth' in Solipsism, and Wittgenstein's Rejection of the A Priori”, European Journal of Philosophy 4, 195-219. 
